\title{
A prevalence survey on leprosy and the possible role of village 10-cell leaders in control in Muheza District, Tanzania
}

\author{
E VAN PRAAG \& S A MWANKEMWA \\ Division of Community Medicine, Faculty of Medicine, Muhimbili \\ Medical Centre, Dar es Salaam, Tanzania
}

Received for publication 5 June 1981

\begin{abstract}
Summary. A total population of 15,029 people in 12 villages was screened for leprosy. The selection of the villages in 2 divisions of Muheza District was based on a proportional cluster sampling method. An overall prevalence estimate of 7.9 per 1,000 was found. Prevalence per village ranged from 0 to 25.8 per 1,000 . The prevalence was related to age and sex and a strong male preponderance was found. The type of leprosy was determined and $55 \%$ were new cases.

Community participation via village 10-cell leaders is assessed with regard to their ability to assist in leprosy control. Their use in promoting drug compliance of the patients and in diminishing the pool of as-yetunidentified and possibly infectious cases is discussed.
\end{abstract}

\section{Introduction}

Detection of leprosy patients by means of screening surveys in communities has always been laborious and difficult. Several factors contribute to this. Low prevalence together with a dispersed rural population in a not-always-easilyaccessible terrain make such an exercise time consuming and laborious.

This is aggravated by the fact that people affected by leprosy still tend to hide their disease and/or are stigmatized by their surrounding community and condemned to live at the outskirts of their village or completely outside their village. ${ }^{1}$

Besides this, it has often been observed that in many areas leprosy patients are unevenly distributed between villages. This makes sampling of people in such areas for the determination of leprosy prevalence more difficult as the convenient approach of sample taking with a few large clusters will not give a 
reliable prevalence estimate. The above constraints have led many investigators to limit their studies to certain easily accessible groups. Often, school surveys for age-specific prevalence determination and case finding or household-contact surveys for active case finding are done.

A recent review ${ }^{2}$ of all surveys and available registration of leprosy patients in Tanzania sums up the situation, but due to limited reliability one has to be careful in drawing conclusions. It seems that the distribution of prevalence is patchy over the regions and even between districts in 1 region. Hyperendemic regions (according to WHO standards more than 10 cases per 1,000 population) appear to be Kigoma, Mwanza, Tabora, Mtwara and Lindi. A major leprosy public health problem (defined by WHO as a prevalence between 1 and 10 per $1,000)$ appears to exist in Mara, Tanga, Singida, Dodoma, Kagera, Ruvuma and Shinyanga. Other regions either lack data or the prevalence is very low, as in Arusha and Kilimanjaro (Fig. 1).

The National Programme on tuberculosis and Leprosy Control in Tanzania (NTLP) was launched in 1977, being the result of the awareness of leprosy as a public health problem. The control measures put emphasis on an integrated approach at primary health-care level throughout the country. Training of available health cadres and concentrating on case detection, case holding for the treatment period and proper treatment are key aspects of the programme.

To enable proper evaluation of the programmes baseline data on the scope of the problem are of utmost importance. Only in this way can the impact of the programme after a certain time period be measured. It was in this view that an extensive village screening survey on leprosy in Muheza District will be a contribution towards the National Tuberculosis and Leprosy Programme.

In addition we wanted to see whether 10-cell leaders* would be able to detect the leprosy patients in their 10 households, and if they could, we could use them to refer the patients in time to the existing health facilities such as village health posts, dispensaries or health centres.

\section{Methodology}

The present study was a part of the training programme in community medicine at the Medical School, Dar es Salaam. A field project on infectious diseases is one of the practical field training programmes which is carried out by medical students in their third year. The aim of the project is to gain practical experience in applied epidemiology. Being in the field, collecting data, analysing it, treating patients at the same time and referring them where necessary adds still more to a community-oriented approach to medical practice.

*Ten-cell leader or balozi: a representative of $c .10$ households, selected by the villages themselves and spokesman for them within the administrative party structure at village level. 
In 1979 leprosy in Muheza District was chosen (Fig. 1). The area is hilly and fertile and agriculture is the main means of subsistence. A few scattered estates also give some regular employment like sisal, red palms or cardamon. The houses are mainly of mud bricks and thatched roofs. The population density is high for Tanzania.

The population of Bwembera and Muheza Division (excluding Muheza township) was our target population. For sampling purposes the population was divided into 60 units or clusters, that is, villages and special category settlements like sisal or cardamon estates.

The average population per sampling unit was 1,523 people. Twelve units covering approximately $20 \%$ of the population of Bwembera and Muheza

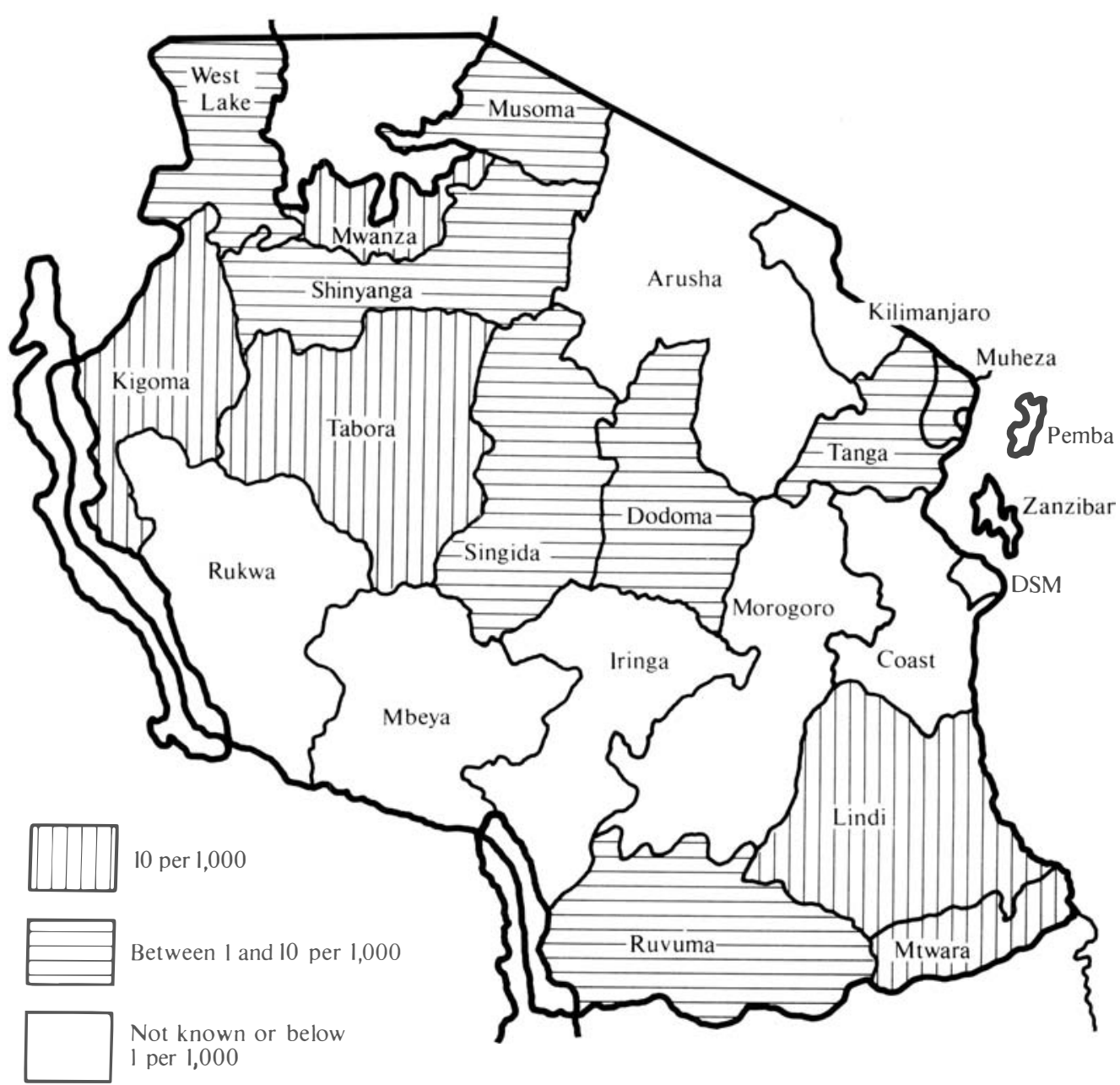

Figure 1. Estimated leprosy prevalence in Tanzania (after Broekmans 1978). 
division were selected in such a way that each unit had a chance proportional to its population size to be in the sample. (A technique called proportional cluster sampling.)

A group of 8-10 students with one leprosy expert covered two villages. There were 6 groups altogether covering 12 villages. Each group screened the whole population in that village systematically with the help of the 10-cell leaders.

Diagnosis of leprosy was tentatively made by the students on clinical grounds and confirmed by the expert either clinically and/or by Ziehl-Neelsen staining of skin smears. Before the field stay students underwent a practical session in the leprosy ward of the Muhimbili Medical Centre diagnosing leprosy, based on examination of skin and nerves.

The activities by the 48 students in the 12 villages took a week. Data analyses were done with the students at the Division of Community Medicine, Muhimbili Medical Centre in Dar es Salaam.

\section{Results}

A total number of 15,029 people were screened during the 1-week survey, being $93 \%$ of the total registered population according to the 1978 census in the villages (Table 1). This shows that considerable coverage can be achieved in such a survey. One cannot expect all people to be at home even if they are informed beforehand.

The under-15 age group in the registered population and in the screened population was 47 and $48 \%$ respectively. Which corresponds with the Tanzanian average of the under- 15 population being around $45 \%$.

The villages show quite a focal distribution of leprosy prevalence (Table 2). A wide range of $0-25.8 \%$ was found. These prevalences differ significantly (Poison dispersion test: $\mathrm{P} / 0.001$ ) with 2 outstanding prevalence rates in Kimbo and Ndondondo villages. Omitting these 2 prevalences the differences between the other villages is not significant $(0.25 / \mathrm{P} / 0.5)$ and just reflects random variation. The total number of cases found was 116 . This number excludes those who do not need treatment any more (10 burnt-out cases). These 116 cases represent a proportion of 7.7 cases per 1,000 of the study population. Taking into account the proportional cluster sampling technique the correct prevalence estimate is 7.9 per 1,000 . This makes leprosy a major public health problem in the 2 divisions in Muheza District. It is of interest to note that the 2 villages with the highest prevalences are geographically close to each other.

For determining the different clinical types of leprosy we used the Madrid field classification with 1 modification that indeterminate cases were grouped as tuberculoid. The majority of cases were tuberculoid (Table 3). This compares with findings from other areas in East Africa where a ratio $\mathrm{T}: \mathrm{B}: \mathrm{L}$ of $80: 10: 10$ is generally found. 
Table 1. Coverage of screened population by age

\begin{tabular}{cccc}
\hline Age (years) & $\begin{array}{c}\text { Total population } \\
\text { in the villages* } \\
\text { No. }\end{array}$ & $\begin{array}{c}\text { Total screened } \\
\text { population } \\
\text { No. }\end{array}$ & Coverage \% \\
\hline $0-1$ & 3,098 & 3,040 & 98 \\
$6-15$ & 4,435 & 4,204 & 95 \\
$16-25$ & 2,333 & 2,139 & 92 \\
$26-35$ & 1,931 & 1,767 & 92 \\
$36-45$ & 1,513 & 1,407 & 93 \\
$46-55$ & 1,068 & 995 & 93 \\
Above 55 & 1,435 & 1,362 & 95 \\
Unknown & 295 & 115 & 39 \\
Total & 16,111 & 15,029 & 93 \\
\hline
\end{tabular}

*According to 1978 census.

Table 2. Distribution of screened population and leprosy cases by villages

\begin{tabular}{lccc}
\hline \multicolumn{1}{c}{ Village } & Screened population & Leprosy cases & Prevalence per 1,000 \\
\hline Ndondondo & 1,738 & 45 & 25.9 \\
Kimbo & 545 & 14 & 25.7 \\
Maduma & 908 & 10 & 11.0 \\
Mkinga Mpakani & 1,341 & 10 & 7.4 \\
Bombani & 1,217 & 7 & 5.7 \\
Magila & 1,695 & 9 & 5.3 \\
Kicheba & 2,477 & 12 & 4.8 \\
Kilongo & 550 & 2 & 3.6 \\
Mwembeni & 957 & 3 & 3.1 \\
Kibaranga & 1,935 & 3 & 1.5 \\
Mgambo & 671 & 1 & 1.5 \\
Makole & 995 & 0 & 0 \\
Total: & 15,029 & 116 & 7.7 \\
\hline
\end{tabular}

The sex ratio male:female among the leprosy patients is $1: 10$, showing a strong male preponderance which is even more explicit from 25 years onwards (Fig. 2).

Many of the patients (55\%) had not been diagnosed earlier as having leprosy, and so had never received any kind of medical treatment (new cases Table 4). Proportionally more males than females were new cases, showing more than twice higher prevalence. This contrasts clearly with the on-treatment

Table 3. Distribution of screened population by type of leprosy (Madrid classification)

\begin{tabular}{lrrc}
\hline Type of leprosy & No & $\%$ & Prevalence per 1,000 \\
\hline Tuberculoid & 83 & 71.6 & 5.5 \\
Borderline & 24 & 20.7 & 1.6 \\
Lepromatous & 9 & 7.8 & 0.6 \\
Total & 116 & 100.1 & 7.7 \\
\hline
\end{tabular}




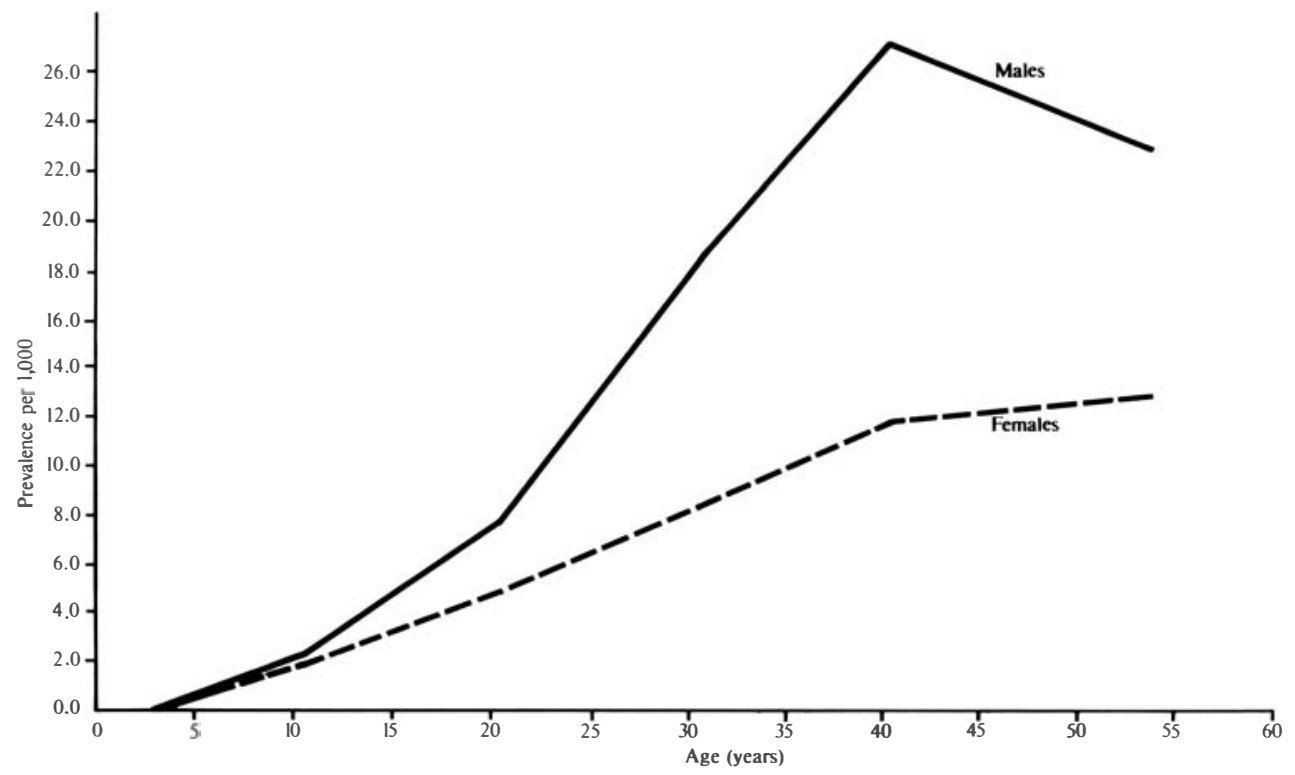

Figure 2. Prevalence of leprosy by age and sex.

cases where the prevalence for males was $4 \%$ and for females $2.7 \%$. Clearly, female patients come much more easily to the clinics compared to males.

The age distribution in the newly diagnosed and the old cases differs considerably (Table 5). Most of the new cases are found in the younger age groups, reflecting under-reporting at health facilities, hence a greater risk of developing disability leading to loss of productivity and esteem in this young age group.

Altogether this 55\%, the newly diagnosed cases found by the students and confirmed by the leprosy experts, contribute to the continuous infection risk

Table 4. Distribution of new and old cases by sex

\begin{tabular}{llclcc}
\hline & \multicolumn{2}{c}{ Male } & \multicolumn{2}{c}{ Female } & \\
Leprosy status & No. & Prev. \% & No. & Prev. \% & T. test on difference \\
\hline Old cases & 30 & 4.0 & 20 & 2.7 & $P=0.16$ \\
New cases & 47 & 6.3 & 19 & 2.5 & $P<0.001$ \\
Total & 77 & 10.3 & 39 & 5.2 & $P<0.001$ \\
\hline
\end{tabular}

Table 5. Distribution of new and old cases by age

\begin{tabular}{lcccccc}
\hline & \multicolumn{2}{c}{ New cases } & \multicolumn{2}{c}{ Old cases } & \multicolumn{2}{c}{ Total } \\
Age (years) & No. & $\%$ & No. & $\%$ & No. & $\%$ \\
\hline $25-$ & 16 & 73 & 6 & 27 & 22 & 100 \\
$26-55$ & 41 & 61 & 26 & 39 & 67 & 100 \\
$56+$ & 7 & 20 & 27 & 80 & 34 & 100 \\
Total & 64 & 55 & 52 & 45 & 116 & \\
\hline
\end{tabular}


Table 6. The ability of 10-cell leaders to screen for leprosy

\begin{tabular}{llccr}
\hline & & \multicolumn{2}{c}{ Diagnosis } & \\
& & Leprosy & No leprosy & Total \\
\hline Opinion & Leprosy & 40 & 6 & 46 \\
Balozi & No leprosy & 86 & 14,897 & 14,983 \\
& Total & 126 & 14,903 & 15,029 \\
\hline
\end{tabular}

Sensitivity, $31.7 \%$. Specificity, $99.9 \%$. Positive predictability, $87 \%$.

of the community as, specifically, the multibacillary non-treated cases are the main source of infection.

Tazania has a very organized rural administrative structure, where since 1974 all rural people are living and registered in villages. Approximately for every 10 households an administrative representative, the 10-cell leader or balozi, is chosen. We could use this advantage in seeking the assistance of the balozi to identify leprosy patients. For this reason their screening ability without prior education on leprosy was tested (Table 6). Burnt-out cases, the ones who do not need treatment any more, were also considered as leprosy cases here, as the balozi cannot differentiate between those burnt out or still in need of treatment so has to refer to the health unit for final judgement.

Out of the 40 confirmed leprosy cases identified by the 10-cell leaders 29 were disabled and the others had lesions on the various parts of the body. Five of the 40 were new cases, of which 4 were not disabled and 1 was a burntout case.

\section{Discussion}

The wide range of prevalences in the different villages confirms the observation of many leprosy workers in Tanzania that the distribution is clustered, even between villages. We looked into reasons for this clustering but could not find any obvious ones as health services, the old/new case distribution, sex and age ratios were roughly similar in all villages studied.

Strong clustering, however, is important for the sampling method as reliability of the prevalence will depend on the increasing number of small clusters one is able to survey.

Sex distribution is another interesting finding for comparison with what is already known in the country.

From the registered cases of most of the regions in Tanzania we find an almost equal sex distribution, but in the community as shown here there is a clear male preponderance. This might indicate that stigma is stronger in males, preventing them from seeking early treatment. 
The data are not yet conclusive as to the desirability of using balozis in the national programme.

Obviously, with a high predictability and specificity they will bring true leprosy patients to the clinics. Many of them are already on treatment (87\%). The importance of this finding lies in the possibility of further strengthening of the compliance to drug therapy of leprosy patients. The balozi hereby acts as a reminder to leprosy patients to adhere to dapsone taking until otherwise advised by the dispensary. However, balozis miss quite a considerable amount of leprosy patients (low sensitivity) and of the ones they send many are already known or disabled.

Maybe, with a particular emphasis on instructing them on leprosy disease, one can expect that they may be able to refer 'suspected leprosy patient' to the clinic, as the balozi is the man of confidence within his community. The rural medical aid at the nearby dispensary could be asked to hold repeated sessions with all village representatives to explain the problem, request their cooperation and teach them accordingly. In this way we have an important tool by which to diminish the 55\% unregistered, which must surely include many infectious cases.

A pilot study to this effect will be needed to test the feasibility of this line of thought.

\section{Acknowledgements}

We wish to thank the third-year medical students (1977-8) of the Faculty of Medicine, University of Dar es Salaam, for their cooperation.

We would also like to thank the 10-cell leaders and the villages for their willingness and cooperation in this survey.

The leprosy experts of the Ministry of Health (Dr W. Kijangwa) and the Tanzania Leprosy Association (Dr Balslev) are gratefully acknowledged for their help during the field stay.

Finally, we thank our colleagues in the Division of Community Medicine.

\section{References}

1 Ruyssenaars JGJM. Leprosy in Mwanza Region, Tanzania (Mimeo). Amsterdam: Royal Tropical Institute, 1978.

2 Broekmans JF. Epidemiological patterns of leprosy in Tanzania. In: Proceedings of the scientific conference on the epidemiology of leprosy. Arusha, Tanzania, 1978. 